\section{Physical Dogma}

On the Explanation of Matter Wave Interference: Towards the End of Indeterministic Physics. By C. W. Rietdijk. Pp. xii +98. (Van Gorcum; Assen, The Netherlands, 1973.) 26 Dutch guilders.

THIs book does not really serve a useful purpose. One may agree with the author that in many respects science is far less rational and far more reactionary than one would wish it to be. As Planck put it in his autobiography: "New ideas are finally accepted, not because their opponents are convinced of the correctness of the ideas, but because they die out." One can also agree with the author that the Copenhagen interpretation of quantum mechanics sometimes greatly resembles a strong vested interest which by some of its adherents is defended with religious fervour. There have, however, been serious discussions of alternatives by eminent physicists, such as De Broglie, Bohm, and Belinfante, and a book which carries the subtitle "Towards the End of Indeterministic Physics" should at least discuss such attempts. Moreover, the discussion should take place in scientific journals. As the author quotes what he feels are objectionable statements by the establishment without giving references and as his arguments lack precision (for instance, retardation effects due to the finiteness of the velocity of light are neglected in a relativistic discussion), I find it very difficult to judge whether or not the author has made any significant contribution to this important discussion.

D. TER HAAR

\section{Jumping the Gap}

Electrical Breakdown in Gases. Edited by J. A. Rees. Pp. ix +291 . (Macmillan: London and Basingstoke, 1973.) $£ 7.95$.

THIs book is comprised of a selection of twenty-five original papers (or extracts) surveying the subject of the electrical breakdown in gases. The papers are conveniently divided into two sections. The first thirteen papers deal with the pre-breakdown conditions prevailing in an initially uniformly electrically stressed gap. The remainder deals, much less thoroughly, with a miscellany of topics including the later stages of breakdown, breakdown in non-uniform fields, corona discharges, lightning and laser induced breakdown.

Most researchers today feel inundated by the written word and I can feel only sympathy for the editor who attempts to sift out just twenty-five papers for special mention. The value of such a collection, however, is crucially dependent on this very subjective selection. In my opinion the first half of the book contains a well chosen array of papers. The classical contributions of such authors as Townsend, Raether and Meek are beyond dispute and these are complemented by an interesting selection of illustrative material to form a well balanced whole. The second part of the book is more controversial. The editor has chosen to include a wide range of topics and, in so doing, has made it difficult to develop them in a convincing manner. Difficult perhaps, but not impossible; the four papers on lightning are, I think, most instructive.

Though the selection of the contributions must be the major concern of editor and reader alike, it is vitally important in such a volume to mould the various papers into some form of contiguous whole. Dr Rees attempts to do this by inserting brief introductions to each paper. They are very brief and, in the first half of the book where the papers themselves have some continuity, I think adequate. But I found them insufficient to rectify the disjointed nature of some parts of the second half of this volume. To supplement the material of this book, the editor has appended short lists of references for further reading. These occur frequently throughout the volume and are of considerable value.

The success of such a collection depends on the purpose it sets out to fulfil. The editor feels that it should be of value to undergraduate and postgraduate students. There are several competing textbooks that seek to serve this same purpose and, in the task of learning the fundamentals of the subject, they are, I have no doubt, to be preferred. However, that is not to deny the interest that this book may engender. The student (as well as his mentor) usually meets the ideas expressed in this book in a mature form, well polished by constant repetition: certainly it is stimulating to recall the original in its more basic state. In a world in which time is not easy to find, however, I suspect that this book will be read as a pleasurable leisure-time activity more than as a utilitarian introduction to the subject.

R. M. BULL

\section{Probability}

An objective Theory of Probability. By D. A. Gillies. Pp. x+250. (Methuen: London, May 1973.) £3.50.

THE author clearly expresses the aim of this book at the beginning of his preface: "To present a philosophical theory of probability which can best be considered as a development of von Mises' views. I am entirely in agreement with von Mises in regarding probability theory as a mathematical science similar to mechanics or electrodynamics, and probability itself as an objective measurable concept similar to mass and charge. In this sense I am presenting an objective theory of probability-as opposed to subjective or logical accounts."

The "subjective or logical" approach also of course has its adherents, for example, Harold Jeffreys or Bruno de Finetti; and the author discusses the rival traditions in the introductory chapter. He then, in part 1, develops Mach's operational approach to scientific concepts, spending perhaps rather excessive time, in a book on probability, on physical concepts such as force and mass. Part 2 contains the systematic development of "objective probability" as an analogous concept, with an axiomatic superstructure designed with the relation with observed frequencies in mind. While modern developments in the study of random sequences, for example, by Kolmogorov and Martin-Löf, are referred to, the author seems to adopt a point of view commonly held, associating the probability concept with a hypothesis of randomness. Whether probabilities can be usefully assigned to single events (Karl Popper's propensity theory, or Eddington's "localization of probability") is considered a somewhat secondary issue.

In part 3 the author faces the problem which this approach, as distinct from the alternative tradition, inevitably raises (it is not automatically to be condemned for that, or other scientific concepts would be similarly condemned): if the so-called objective probability is in part a hypothetical concept, how do we justify making use of it? He appeals to the "hypotheticaldeductive approach" represented by Karl Popper and E. B. Braithwaite, in which scientific hypotheses are set up to be falsified rather than established. The special difficulty, that statements involving probabilities can never be strictly falsified, is discussed at some length (chapters 8,9 , and 10 ), with some final comments on the status of the Neyman-Pearson theory of testing hypotheses, as the author sees it. In spite of some sympathy with the author's general standpoint, I found this part of the book somewhat inconclusive reading. The book, as a whole, however, is very readable; even if it is unlikely to resolve so longstanding a controversy as to how probability should be used in science, or to justify the claim (see wording on the paper jacket) that "the book presents a new and rival theory of probability", the reader should have more understanding of probability after he has read the book than he did before. Past experience with other works on probability suggests that one should not expect more than this.

M. S. BARTLETT 